\title{
Epidemiological Analysis Using Pulsed-Field Gel Electrophoresis of Salmonella enteritidis Outbreak in Factory Workers
}

\author{
Fulya Bayindir Bilman, ${ }^{1, *}$ Baris Cicek, ${ }^{2}$ Revasiye Gulesen, ${ }^{3}$ and Belkis Levent ${ }^{3}$ \\ ${ }^{1}$ Izmir Menemen State Hospital, Department of Medical Microbiology, Turkey \\ ${ }^{2}$ Izmir Menemen State Hospital, Department of Infectious Disease, Turkey \\ ${ }^{3}$ National Enteric Pathogens Reference Laboratory, Public Health Institution of Turkey \\ "Corresponding author: Fulya Bayındır Bilman, MD, Specialist (Medical Microbiology), Izmir Menemen State Hospital, Department of Medical Microbiology, Izmir, Turkey. Tel: \\ +90-5052798330, Fax: +90-2328325851, E-mail: f_bilman@hotmail.com
}

Received 2017 March 07; Revised 2017 May 27; Accepted 2017 June 24.

\begin{abstract}
Background: Salmonellosis is still being reported as the second most common food-borne infection of bacterial origin. The most common serotypes worldwide as salmonellosis agents are Salmonella enterica subsp. enterica serotype enteritidis (S. enteritidis) and S. enterica subsp. enterica serotype typhimurium (S. typhimurium).

Objectives: In the current study, the researchers investigated food associated S. enteritidis outbreak in factory workers of Turkey. Methods: The same meatball preparation that was consumed by the patients for lunch and dinner was responsible for the food poisoning on July 2014, when 257 workers in the same factory sought medical care. Among 257 individuals with diarrhea, abdominal pain, headache, fever, and vomiting, 48 (19\%) were hospitalized. Stool samples were plated on Salmonella-Shigella agar and Eosine Methylene Blue agar plates and incubated at $37^{\circ} \mathrm{C}$. Colonies morphologically resembling Salmonellae were selected for further identification on the next day using API $20 \mathrm{E}$.

Results: During the outbreak, 10 out of 48 (21\%) stool samples and 1 out of 25 (4\%) blood culture from patients were positive. On serotyping, the isolates were identified as S. enteritidis (9,12; g,m;-) by the agglutination test. Pulsed field gel electrophoresis (PFGE) used for epidemiological analysis of the isolates showed a similar PFGE pattern. Pulsed field gel electrophoresis analysis was performed by XbaI enzymes. The antibiotic susceptibility tests of isolates were studied according to clinical and laboratory standards institute (CLSI) suggestions by using the disc diffusion method. All isolates were susceptible to ampicillin, nalidixic acid, ciprofloxacin, trimethoprim/sulfamethoxazole, tetracycline, kanamycin, chloramphenicol, gentamicin, ceftazidime, and cefotaxime.

Conclusions: All patients in the study were treated with ciprofloxacin $2 \times 750 \mathrm{mg} /$ day and returned to work on the 7 th day.
\end{abstract}

Keywords: Outbreak, Pulsed Field Gel Electrophoresis, Antimicrobial Susceptibility, Salmonella enteritidis

\section{Background}

Of the infectious agents that are transmitted through food, the ones with the largest share are Salmonella species. The transmission pathways of Salmonella spp. isolates to humans include contaminated food, undercooked meat, and eggs (1). Salmonella enteritidis are bacteria that have been known for 125 years, and have maintained their importance as an infectious agent in humans. The U.S. FoodNet surveillance program reported that Salmonella serotypes were the second leading cause of bacterial foodborne infections in 2004, with 5 serotypes accounting for $59 \%$ of the Salmonella infections (2). The serotypes called Typhimurium, Enteritidis, and Newport are the most common. In the recent years, approximately 1.5 million gastroenteritis cases in the USA were caused by $S$. enterica serovars. Widespread infection is still an important public health issue (3).

Reliable methods should be preferred for accurate epidemiological analysis of salmonellosis outbreaks. Among the microbiological analyzes, the most preferred methods are culture tests, biochemical tests, serotype determination, and phage type. During the last 2 decades, the recommended surveillance techniques have been DNA based (4). As a molecular method, the pulsed-field gel electrophoresis (PFGE) method, which has been preferred by CDC since the early 1990s, remains the gold standard (5-7).

It is important for all phases to be under control in the process of preparing food. All stages, starting from live animals, especially farm products, to the cooking stage must be perfomed with caution. Surveillance programs to monitor contamination with Salmonella must include the whole food chain at regular intervals for preventing food-borne Salmonella infections (8). Sanitary measures for preventing Salmonella contamination necessitates obtaining uncontaminated feeds, controlling rodents, and wild birds, while restricting the flow of personnel, equipment, and air to "clean" areas, maintaining the sanitation of transport vehicles. In addition, Salmonella in feeds may be eliminated by thermal and chemical processing (9). 


\section{Objectives}

In the current study, the researchers investigated food associated S. enteritidis outbreak in factory workers of Turkey.

\section{Methods}

Medical treatment was sought by 257 ill individuals, who were kept in the emergency area for observation. Among 257 patients with diarrhea, abdominal pain, headache, fever and vomiting, 48 (19\%) were hospitalized. All cases were male. Stool samples were plated on Salmonella-Shigella agar (Salubris, Turkey), Eosine Methylene Blue agar (Salubris, Turkey), and 5\% sheep blood agar (Salubris, Turkey). Plates were incubated at $37^{\circ} \mathrm{C}$ for 18 to 24 hours. Suspected colonies were selected for further identification on the next day, using API 20E (BioMerieux, France). Isolates were sent to reference laboratories for further serotyping. Conventional serotyping was conducted at the national enteric pathogens reference laboratory, public health institution of Turkey under the national enteric pathogen laboratory surveillance Network (EPLA). In the Reference Laboratory, through the Kauffmann-White scheme, $\mathrm{O}$ (Somatic), Vi (capsular), and $\mathrm{H}$ (flajella) antigens (Public Health Institution, Turkey) were formulated and the serotype was assigned.

Pulsed field gel electrophoresis was used for the epidemiological analysis of isolates and PFGE analysis was performed by XbaI macrorestriction enzyme, according to the world health organization protocols (10). Antimicrobial susceptibility was determined by disc diffusion method as recommended by CLSI (11). Mueller-Hinton agar (Salubris, Turkey) was used for all strains. The antibiotic discs included ampicillin, chloramphenicol, kanamycin, tetracycline, gentamicin, trimethoprim-sulfamethoxazole, nalidixic acid, ceftazidime, cefotaxime, and ciprofloxacin (BD, Diagnostic Systems, USA). Escherichia coli ATCC 25922 was used as the control strain.

All food and water samples were also collected and investigated by the Public Health Institution of Izmir. Food samples (soup, meatball, etc.) were investigated for the detection of microbiological contamination level. The study was approved by the ethics committee of Izmir Ataturk Education and Research Hospital on the 21st of May, 2015 (code 101).

\subsection{Ethics Statement}

The study was approved by the ethics committee of Izmir Ataturk Education and Research Hospital on the 21st of May, 2015 (code 101).

\section{Results}

During the outbreak, 10 out of 48 (21\%) stool samples and 1 out of 25 (4\%) blood culture from patients were positive. All patients were male. Despite being rare,1 Salmonella spp. isolate was isolated from the blood culture of a 46year-old male patient. A predisposing disease was not detected.

The lactose non-fermenting colonies on the Salmonella-Shigella agar plates were identified as $S$. enterica ssp enterica by API 20E (BioMerieux, France) in stool samples. Ten out of eleven strains were found in cases as S. enteritidis ( 9,12 ; g,m; -) serotype with the agglutination test. Outbreaks were caused by the same Salmonella serotype. By PFGE, 10 identical S. enteritidis patterns were shown with enzyme XbaI. Results showed that they all belonged to group D, S. enteritidis (9,12; g,m; -). One isolate showed a different pattern. This was considered as a sporadic case (Figure 1$)$. All isolates $(n=11)$ were susceptible to ampicillin, nalidixic acid, ciprofloxacin, trimethoprim/sulfamethoxazole, tetracycline, kanamycin, chloramphenicol, gentamicin, ceftazidime, and cefotaxime. All patients were succesfully treated with ciprofloxacin 2 $\times 750 \mathrm{mg} /$ day for 5 days and returned to work on the 7 th day.

Figure 1. Image of the PFGE Analysis Performed by Xbal Macrorestriction Enzyme

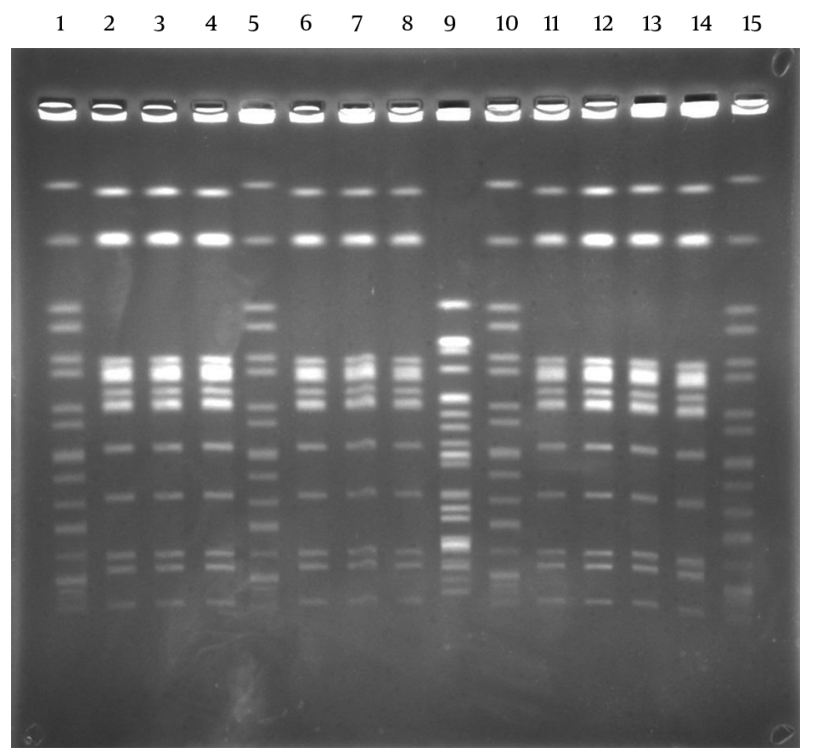

Lane 1, 5,10,15: S. Braenderup; lane 2, 3, 4, 6, 7, 8,11,12,13,14: Same S. enteritidis patterns of different patients; 9 : different Salmonella enterica ssp enterica pattern of a patient.

Food workers in the same factory had been monitored by culture of stool samples. Therefore, samples were collected and processed in a medical microbiology laboratory 
from food-handlers in the same factory. None of them were observed in the presence of Salmonellae. However, S. enteritidis was detected in one item of the food (meatball), which was consumed by the subjects by public health institution laboratory of Izmir. Results of the study showed that meatballs contaminated with $S$. enteritidis $(9,12 ; \mathrm{g}, \mathrm{m}$; -) were responsible for this outbreak. The same S. enteritidis strain was isolated from meatball and soup by the National Food Reference Laboratory/Turkey in this outbreak. This outbreak was concluded to have been caused by staff members of the factory, who contaminated the meatball during processing with eggs or meat products. Although meat products and eggs were kept under appropriate conditions for consumption in the factory kitchen, conditions of hygiene and sanitation were not considered susceptible enough from production till consumption.

\section{Discussion}

Salmonella enteritidis are bacteria that have been known for 125 years, and have maintained their importance as an infectious agent in humans. The first symptoms in the body after becoming infected are fever, stomachache, and diarrhea. The stated onset periods range between 12 and 72 hours. Infection becomes limited during 7 days, generally automatically or with antibiotic treatment. The course may be severe in elderly, children, and those with immune system failure. Therefore, inservice treatment in a hospital is advised as the infection that has started in the digestive system may spread to the entire body through the blood (12). Salmonella spp. infections could have mild or no symptoms, yet the pathogen could continue to be excreted from the body for up to 3 months after recovery (13).

About 400 people are known by CDC to die of acute salmonellosis in one year. Salmonella enteritidis is one of the most common serotypes of Salmonella reported worldwide (14). The number of outbreaks of $S$. enteritidis rose dramatically in the past 30 years (6). Salmonella enteritidis are the most commonly reported serotype (36\%) in Turkey (15-17), as Salmonella spp. could survive in high temperatures, high fat, and low water content conditions (18). Contamination by direct contact occurs easily because they are present in the intestines of some mammals and poultry. Most of the infections were caused by contamination from poultry or egg products (19-21). In S. enteritidis infections, egg shell has an important role in the pathways of transmission through food. Infection develops after contaminated eggs are consumed. Other sources, such as raw milk, pork, beef, sprouts, and raw almonds are known less frequently. According to CDC data, travel-related Salmonella infections and carriage are seen after traveling to Asian and African countries, primarily Latin America. As reported previously $38 \%$ of all travel-related Salmonella cases reported by the CDC developed after travel to Mexico (2224).

Overall, 176.395 Salmonella spp. cases in foodborne outbreaks until 2005 were reported in European Union countries. The most common source of outbreaks was eggs (25). Salmonella enteriditis and S. typhimurium are the most commonly reported serotype in this period. Salmonella enteritidis/S. typhimurium positivity rates were $20.4 \%$ in chicken and egg farms (26-29). In the USA, 1939 cases were reported in the epidemics from many regions from 1st of May to 30 th of November, 2010, and the causing agent was S. enteritidis. These infections were associated with egg shells (6).

Again in 2014, 87 people were reported from 11 different states in S. enteritidis epidemics. In the course of an epidemic, 14 patients out of $52(27 \%)$ had to be treated as inpatients. No death was reported (6). Local public health officials also performed traceback. The results of investigations on the source of these epidemics were related to bean sprouts. The strains isolated in antibiotic susceptibility test were reported to be susceptible. As of November, 2010, nine different survey protocols were prepared in the European Union -countries. Salmonella spp. analysis was included in these protocols in packing centers and eggs, which are sold in markets and shops (26). The control program was implemented in laying hens since 2008 in Turkey (30).

Oktem et al. Reported that 8 minutes of boiling was needed for the bacterium to become ineffective. It was pointed out in this study that Salmonella bacteria could still remain alive at the end of the $21 s t$ day at $4^{\circ} \mathrm{C}$ (31). It is necessary to avoid the consumption of undercooked egg and foods infected through touch with egg shells, especially for children, elderly and patients with immune system failure. Among protective precautions, washing hands with water and soap after contact with raw eggs is of great importance. Similarly, when there is a touch with surfaces, it is necessary to make the surface clean with chemical matters that provide special hygiene that could eradicate the bacteria. It is necessary for raw eggs to not be held at room temperature in order to reduce the risk factor on this issue. Eggs with dirty or cracked shells are not advised.

Pulsed field gel electrophoresis is commonly used to detect and identify the epidemic relationship between pathogens and meats. Each bacterial species was known by its unique DNA structure. The method, known as PFGE, is used to achieve this unique fingerprint (32-34). Ashtiani et al. (35) detected that ampicillin, amikacin, and chloramphenicol resistance among Salmonella spp. had increased between 1996 and 2005. There has been no significant change in cephalothin, trimethoprim-sulfamethoxazole, 
ceftazidime, and gentamicin resistance in this study.

Kesli et al. (36) reported that ampicillin resistance was determined as $63 \%$. In addition, chloramphenicol $61 \%$, cefuroxime $56 \%$, ceftriaxone $49 \%$, tetracycline $8 \%$, trimethoprim-sulfamethoxazole $3 \%$, ciprofloxacin $3 \%$, and meropenem $2 \%$ were found resistant in that study, in Salmonella spp isolates $(\mathrm{n}=326)$. Kesli et al. detected that all strains were susceptible to amikacin and cefazolin (36). When they sorted out the percentages of isolates, Salmonella serotype enteritidis 171 (52.4\%) was found in the first place. Then, ranking continued as follows: Salmonella serotype typhimurium, 143 (43.9\%), Salmonella serotype gallinarum, 7 (2.1\%) and Salmonella serotype paratyphi A, 5 (1.5\%). Erdem et al. reported an increase in resistance to ciprofloxacin (MIC > or $=0.125 \mathrm{mg} / \mathrm{L}$ ) in S. typhimurium, $S$. paratyphi $\mathrm{B}$, and $S$. enteritidis strains and that result has an emerging problem in S. enterica in Turkey (17).

As indicated by different studies around the world, an overall significant increase in resistance to ampicillin (14\% to $50 \%$ ), and nalidixic acid (10\%), tetracycline (30\%), and erythromycin (72\%) was reported from different regions (37). Fortunately, trimethoprim/sulphamethoxazole, gentamicin, kanamycin, and chloramphenicol were reported susceptible in many areas. Chu et al. reported that $S$. enterica serotype enteritidis isolates (serotype 1a) has remained relatively more drug-susceptible than other common serotypes derived from human sources, such as $S$. enterica serotypes typhimurium (37). It was also reported that ciprofloxacin resistance rate was $8.05 \%$ (147/1826) in China (38). Resistance to ampicillin, chloramphenicol, and nalidixic acid were $20 \%, 11 \%$, and $2.7 \%$, respectively, in the United States (39). Surveillance programmes should be tracked carefully because of the extensive use of antibiotics in livestock production $(40,41)$.

\section{Conclusion}

In summary, it is recommended for health authorities to follow the regulations of the tracking food poisoning outbreaks. In food poisoning, the manual for infectious specimen collection must be known to collect samples from possible sources and food handlers in order to meet the need for disease prevention. This will help identify the true source of the disease. Restaurant and kitchen workers need to pay attention to personal and food hygiene, and to stop handling food when they have gastrointestinal symptoms. This is the best way to prevent food poisoning.

\section{Footnotes}

Authors' Contribution: Study concept and design: Fulya Bayindir Bilman; acquisition of data: Fulya Bayindir Bilman and Baris Cicek; analysis and interpretation of data: Fulya Bayindir Bilman and Revasiye Gulesen; drafting of the manuscript: Fulya Bayindir Bilman; critical revision of the manuscript for important intellectual content: Fulya Bayindir Bilman; administrative, technical, and material support: Revasiye Gulesen, and Belkis Levent. Study supervision: Fulya Bayindir Bilman.

Financial Disclosure: No funding/support was provided.

\section{References}

1. Scallan E, Hoekstra RM, Angulo FJ, Tauxe RV, Widdowson MA, Roy SL, et al. Foodborne illness acquired in the United States-major pathogens. Emerg Infect Dis. 2011;17(1):7-15. doi: 10.3201/eid1701.P11101. [PubMed: 21192848].

2. Centers for Disease C. Preliminary FoodNet data on the incidence of infection with pathogens transmitted commonly through foodselected sites, United States, 2003. MMWR Morb Mortal Wkly Rep 2004;53(16):338-43. [PubMed: 15123986].

3. Voetsch AC, Van Gilder TJ, Angulo FJ, Farley MM, Shallow S, Marcus R, et al. FoodNet estimate of the burden of illness caused by nontyphoidal Salmonella infections in the United States. Clin Infect Dis. 2004;38 Suppl 3:S127-34. doi: 10.1086/381578. [PubMed: 15095181].

4. Foley SL, Zhao S, Walker RD. Comparison of molecular typing methods for the differentiation of Salmonella foodborne pathogens. Foodborne Pathog Dis. 2007;4(3):253-76. doi: 10.1089/fpd.2007.0085. [PubMed: 17883310].

5. Garaizar J, Lopez-Molina N, Laconcha I, Lau Baggesen D, Rementeria A, Vivanco A, et al. Suitability of PCR fingerprinting, infrequentrestriction-site PCR, and pulsed-field gel electrophoresis, combined with computerized gel analysis, in library typing of Salmonella enterica serovar enteritidis. Appl Environ Microbiol. 2000;66(12):5273-81. [PubMed: 11097902].

6. CDC . Multistate Outbreak of Human Salmonella Enteritidis Infections Associated with Shell Eggs (Final Update) Centers for Disease Control and Prevention; 2015. Available from: http://www.cdc.gov/ pulsenet.

7. Swaminathan B, Barrett TJ, Hunter SB, Tauxe RV, C. D. C. PulseNet Task Force . PulseNet: the molecular subtyping network for foodborne bacterial disease surveillance, United States. Emerg Infect Dis. 2001;7(3):382-9. doi: 10.3201/eid0703.010303. [PubMed: 11384513].

8. Bertrand S, Dierick K, Heylen K, De Baere T, Pochet B, Robesyn E, et al. Lessons learned from the management of a national outbreak of Salmonella ohio linked to pork meat processing and distribution. $J$ Food Prot. 2010;73(3):529-34. [PubMed: 20202340].

9. Jones FT. A review of practical Salmonella control measures in animal feed.J Appl Poultry Res. 2011;20(1):102-13. doi: 10.3382/japr.2010-00281.

10. Hendriksen RS. A global Salmonella surveillance and laboratory support project of the World Health Organization: Laboratory Protocols Level 1 Training Course Identification of Salmonella. ; 2003.

11. Clinical and Laboratory Standards Institute(CLSI). Performance standards for antimicrobial susceptibility testing; Twenty-Third informational supplement, M100-S24. ; 2014

12. Imen BS, Ridha M, Mahjoub A. In: Salmonella-A Dangerous Foodborne Pathogen. Barakat S, Mahmoud M, editors. InTech; 2012. Laboratory typing methods for diagnostic of Salmonella strains, the "old" organism that continued challenges. 
13. McLauchlin J, Little C, Hobbs BC. Hobbs' Food Poisoning and Food Hygiene, Seventh Edition, Part 5. USA: CRC Press Health Protection Agency Centre for Infections; 2007.

14. Boore AL, Hoekstra RM, Iwamoto M, Fields PI, Bishop RD, Swerdlow DL. Salmonella enterica Infections in the United States and Assessment of Coefficients of Variation: A Novel Approach to Identify Epidemiologic Characteristics of Individual Serotypes, 1996-2011. PLoS One. 2015;10(12):e0145416. doi: 10.1371/journal.pone.0145416. [PubMed: 26701276].

15. Kayali GR, Sezen Sevimli F, UEPLA working group members . Analysis of the first three months of UEPLA data. Turk Hij Den Biyol Derg. 2008;65(1):1-3.

16. Erdem B, Hascelik G, Gedikocglu S, Gur D, Ercis S, Sumerkan B, et al. [Salmonella enterica serotypes and Salmonella infections: a multicenter study covering ten provinces in Turkey]. Mikrobiyol Bul. 2004;38(3):173-86. [PubMed: 15490836].

17. Erdem B, Ercis S, Hascelik G, Gur D, Gedikoglu S, Aysev AD, et al. Antimicrobial resistance patterns and serotype distribution among Salmonella enterica strains in Turkey, 2000-2002. Eur J Clin Microbiol Infect Dis. 2005;24(3):220-5. doi: 10.1007/s10096-005-1293-y. [PubMed: 15772822].

18. Foley SL, Lynne AM. Food animal-associated Salmonella challenges: pathogenicity and antimicrobial resistance. J Anim Sci. 2008;86(14 Suppl):E173-87. doi: 10.2527/jas.2007-0447. [PubMed: 17878285].

19. Schroeder CM, Naugle AL, Schlosser WD, Hogue AT, Angulo FJ, Rose JS, et al. Estimate of illnesses from Salmonella enteritidis in eggs, United States, 2000. Emerg Infect Dis. 2005;11(1):113-5. doi: 10.3201/eid1101.040401. [PubMed: 15705332].

20. Kim YJ, Chon JW, Lim JS, Song BR, Seo KH, Heo EJ, et al. Traceback investigation for Salmonella contamination at egg processing plants in South Korea: prevalence, antibiotic resistance, and epidemiological tracing by rep-PCR fingerprinting. J Food Sci. 2015;80(4):M759-64. doi: 10.1111/1750-3841.12731. [PubMed: 25702609].

21. Todd EC, Michaels BS, Smith D, Greig JD, Bartleson CA. Outbreaks where food workers have been implicated in the spread of foodborne disease. Part 9. Washing and drying of hands to reduce microbial contamination. J Food Prot. 2010;73(10):1937-55. [PubMed: 21067683].

22. Kendall ME, Crim S, Fullerton K, Han PV, Cronquist AB, Shiferaw B, et al. Travel-associated enteric infections diagnosed after return to the United States, Foodborne Diseases Active Surveillance Network (FoodNet), 2004-2009. Clin Infect Dis. 2012;54 Suppl 5:S480-7. doi: 10.1093/cid/cis052. [PubMed: 22572673].

23. O'Donnell AT, Vieira AR, Huang JY, Whichard J, Cole D, Karp BE. Quinolone-resistant Salmonella enterica serotype Enteritidis infections associated with international travel. Clin Infect Dis. 2014;59(9):e139-41. doi: 10.1093/cid/ciu505. [PubMed: 24973311].

24. CDC . Infectious Diseases Related to Travel Centers for Disease Control and Prevention; 2017. Available from: https: //wwwnc.cdc.gov/travel/yellowbook/2016/infectious-diseasesrelated-to-travel/salmonellosis-nontyphoidal.

25. EFSA. The community summary report on trends and sources of zoonoses, zoonotic agents, antimicrobial resistance and foodborne outbreaks in the European Union in 2006. EFSA Journal. 2007;130:38105.

26. Scientific Opinion on a review on the European Union . Scientific Opinion on a review on the European Union Summary Reports on trends and sources zoonoses, zoonotic agents and foodborne outbreaks in 2009 and 2010 - specifically for the data on Salmonella, Campylobacter, verotoxigenic Escherichia coli, Listeria monocytogenes and foodborne outbreaks. EFSA J. 2012;10(6) doi: 10.2903/j.efsa.2012.2726.

27. Henao OL, Jones TF, Vugia DJ, Griffin PM, Foodborne Diseases Ac- tive Surveillance Network W. Foodborne Diseases Active Surveillance Network-2 Decades of Achievements, 1996-2015. Emerg Infect Dis. 2015;21(9):1529-36. doi: 10.3201/eid2109.150581. [PubMed: 26292181].

28. Centers for Disease C. Preliminary FoodNet data on the incidence of infection with pathogens transmitted commonly through food - 10 states, 2009. MMWR Morb Mortal Wkly Rep. 2010;59(14):418-22. [PubMed: 20395935].

29. Gormley FJ, Little CL, Rawal N, Gillespie IA, Lebaigue S, Adak GK. A 17-year review of foodborne outbreaks: describing the continuing decline in England and Wales (1992-2008). Epidemiol Infect. 2011;139(5):688-99. doi: 10.1017/S0950268810001858. [PubMed: 20696086].

30. Ozkok S. Increasing Risk of Salmonella spp. in table eggs. J Nat Food Ref Lab. 2011;2(3):27-33.

31. Oktem AB, Onurdag FK, Er B, Demirhan B. A research of Salmonella spp. in egg and egg products and survival of Salmonella in different temperatures. TurkJ Pharm Sci. 2009;6:147-54.

32. Peters TM, Berghold C, Brown D, Coia J, Dionisi AM, Echeita A, et al. Relationship of pulsed-field profiles with key phage types of Salmonella enterica serotype Enteritidis in Europe: results of an international multi-centre study. Epidemiol Infect. 2007;135(8):1274-81. doi: 10.1017/S0950268807008102. [PubMed: 17306053].

33. Cardinale E, Perrier Gros-Claude JD, Rivoal K, Rose V, Tall F, Mead GC, et al. Epidemiological analysis of Salmonella enterica ssp. enterica serovars Hadar, Brancaster and Enteritidis from humans and broiler chickens in Senegal using pulsed-field gel electrophoresis and antibiotic susceptibility. J Appl Microbiol. 2005;99(4):968-77. doi: 10.1111/j.1365-2672.2005.02618.x. [PubMed: 16162250].

34. Aktas Z, Day M, Kayacan CB, Diren S, Threlfall EJ. Molecular characterization of Salmonella Typhimurium and Salmonella Enteritidis by plasmid analysis and pulsed-field gel electrophoresis. Int J Antimicrob Agents. 2007;30(6):541-5. doi: 10.1016/j.ijantimicag.2007.06.034. [PubMed: 17900873].

35. Ashtiani MT, Monajemzadeh M, Kashi L. Trends in antimicrobial resistance of fecal Shigella and Salmonella isolates in Tehran, Iran. Indian J Pathol Microbiol. 2009;52(1):52-5. [PubMed:19136781].

36. Kesli R, Bilgin H, Pirgon O, Feyzioglu B, Guzelant A. Investigation of Antimicrobial Resistance in Salmonella and Shigella Strains Isolated from Fecal Samples in Children During 2008-2011. Türk Mikrobiyol Cem Derg. 2012;42(2):66-72.

37. Khumalo J, Saidi B, Mbanga J. Evolution of antimicrobial resistance of Salmonella enteritidis (1972-2005). Onderstepoort J Vet Res. 2014;81(1) doi: 10.4102/ojvr.v81i1.807. [PubMed: 25686362].

38. Liang Z, Ke B, Deng X, Liang J, Ran L, Lu L, et al. Serotypes, seasonal trends, and antibiotic resistance of non-typhoidal Salmonella from human patients in Guangdong Province, China, 2009-2012. BMC Infect Dis. 2015;15:53. doi: 10.1186/s12879-015-0784-4. [PubMed: 25881319].

39. Crump JA, Medalla FM, Joyce KW, Krueger AL, Hoekstra RM, Whichard $\mathrm{JM}$, et al. Antimicrobial resistance among invasive nontyphoidal Salmonella enterica isolates in the United States: National Antimicrobial Resistance Monitoring System, 1996 to 2007. Antimicrob Agents Chemother. 2011;55(3):1148-54. doi: 10.1128/AAC.01333-10. [PubMed: 21199924].

40. Kirk MD, Pires SM, Black RE, Caipo M, Crump JA, Devleesschauwer $\mathrm{B}$, et al. World Health Organization Estimates of the Global and Regional Disease Burden of 22 Foodborne Bacterial, Protozoal, and Viral Diseases, 2010: A Data Synthesis. PLoS Med. 2015;12(12):e1001921. doi: 10.1371/journal.pmed.1001921. [PubMed: 26633831].

41. Frasson I, Bettanello S, De Canale E, Richter SN, Palu G. Serotype epidemiology and multidrug resistance patterns of Salmonella enterica infecting humans in Italy. Gut Pathog. 2016;8:26. doi: 10.1186/s13099016-0110-8. [PubMed: 27252785]. 